\title{
甲状腺素对大鼠心脏肾上腺素受体的调节*
}

许开明曲鹏禹更生 韩启德

(北京医科大学第三医院血管医学研究所, 北京 100083)

\section{关键词肾上腺素受体 心脏甲状腺靑}

心脏是甲状腺素作用的主要靶器官之一, 甲状腺机能的改变常常伴有心脏功能的异常. 其中最主要表现之一就是对交感 - 儿茶酚胺反应性的改变 ${ }^{[1]}$. 已有研究表明这些变化与心脏 肾上腺素受体密度的改变密切相关. 在甲状腺机能立进时大鼠心脏 $\beta$ - 肾上腺素受体 $(\beta-\mathrm{AR})$ 上调, $\alpha_{1}$ - 肾上腺素受体 $\left(\alpha_{1}-\mathrm{AR}\right)$ 下调; 在甲状腺机能减低时心脏 $\beta-\mathrm{AR}$ 下调, 而 $\alpha_{1}-\mathrm{AR}$ 的变化报道不一 ${ }^{[2,3]}$. 心脏 $\alpha_{1}-\mathrm{AR}$ 可分成 $\alpha_{1 \mathrm{~A}}, \alpha_{1 \mathrm{~B}}, \alpha_{1 \mathrm{D}} 3$ 种亚型, 心脏 $\beta-\mathrm{AR}$ 可分 成 $\beta_{1}, \beta_{2}$ 两种亚型. 对甲状腺机能改变时心脏 $\alpha_{1}-\mathrm{AR}$ 与 $\beta-\mathrm{AR}$ 上述亚型的改变则至今少 见报道. 本文采用半定量逆转录聚合酶链反应 (RT-PCR) 方法测定大鼠甲状腺机能改变时 心脏 $\alpha_{1}-\mathrm{AR}$ 及 $\beta-\mathrm{AR}$ 各亚型 $\mathrm{mRNA}$ 水平的改变, 从基因转录水平上观察甲状腺素对大鼠心 脏肾上腺素受体的调节作用.

\section{1 材料与方法}

\section{1 动物}

雄性 Wistar 大鼠, 体重 $220 \pm 15 \mathrm{~g}$. 经腹腔注射 $\mathrm{L}-\mathrm{T}_{4}(200 \mu \mathrm{g} / 100 \mathrm{~g}$ 体重/d,10 d ) 或在饮水中 加人 $0.2 \%$ 2-thiouracid, 20 d, 造成甲状腺机能立进或减低, 对照组分别注射生理盐水或饮不含 药的水. 到期用 $20 \%$ 乌拉坦 ( $5 \mathrm{~mL} / \mathrm{kg}$ 体重) 腹腔注射麻醉大鼠, 经腹主动脉取血, 然后取心 脏, 立即存放液氮中保存. 采用放射免疫分析法测定血浆 $\mathrm{T}_{3}, \mathrm{~T}_{4}$ 浓度.

\section{2 大鼠心脏 RNA 提取}

根据异硫氧酸胍 - 酚: 氯仿抽提一步法提取心脏总 $\mathrm{RNA}^{[4]}$. 为了消除 DNA 的污染, 取 $10 \mu \mathrm{g}$ 总 RNA在含有 $40 \mathrm{mmol} \cdot \mathrm{L}^{-1}$ Tris- $\mathrm{HCl}(\mathrm{pH} 7.9), 10 \mathrm{mmol} \cdot \mathrm{L}^{-1} \mathrm{NaCl}, 6 \mathrm{mmol} \cdot \mathrm{L}^{-1} \mathrm{MgCl}_{2}$, $25 \mathrm{U}$ RNasin, $10 \mathrm{U}$ DNase 溶液中 $37^{\circ} \mathrm{C}$ 水浴 $30 \mathrm{~min}$, 然后用等体积酚: 氯仿 $(1: 1 \mathrm{v} / \mathrm{v})$ 抽提, 乙 醇沉淀, 干燥, 最后溶于 $10 \mu \mathrm{LDEPC}-$ 处理水中.

\section{3 逆转录反应}

在 $25 \mu \mathrm{L}$ 反应体系中含有经 DNase 处理过的 RNA $5 \mu \mathrm{g}, 0.1 \mu \mathrm{g}$ Oligo(dT), 10U AMV 逆 转录酶等在 $42^{\circ} \mathrm{C}$ 水浴 $1 \mathrm{~h}$, 阴性对照除不含 $\mathrm{AMV}$ 逆转录酶外, 与上述反应完全相同.

\section{$1.4 \alpha_{1}-\mathrm{AR}$ 和 $\beta-\mathrm{AR}$ 各亚型及 $\beta$-actin 的 PCR 扩增}

由于肾上腺素受体基因在第三细胞内环所对应区有很高的异源性, 因此选择此区用于 PCR

1995-03-23 收稿, 1995-06-30 收修改稿

*美国中华医学基金会资助项目 
扩增, 以 $\beta$-actin 作为本实验参照物. 其引物分别为:
$\alpha_{1 \mathrm{~A}}-\mathrm{AR}$
1: 5'-CGAGGCCTCAAGTCCGGCCT-3'
2: 5'-CTCTCGAGAAAACTTGAGCAG-3'
$\alpha_{1 \mathrm{~B}}-\mathrm{AR}$
1: 5'-ATCGTGGCCAAGAGGACCAC-3'
2: 5'-CGGGAGAGCGATGAAGAAGG-3'
$\alpha_{1 \mathrm{D}}-\mathrm{AR}$
1: 5'-CGTGTGCTCCTTCTACCTACC-3'
2: 5'-GCACAGGACGAAGACACCCAC-3'
$\beta_{1}-\mathrm{AR}$
1: 5'- GGGCAACGTGTTGGTGATCG-3'
2: 5' -CTGGCCGTCACACATAGCAC-3'
$\beta_{2}-\mathrm{AR}$
1: 5'-GAGACCCTGTGCGTGATTGC-3'
2: 5'-CCTGCTCCACCTGGCTGAGG-3'
$\beta$-actin
1: 5'-GAGACCTTCAACACCCCAGCC-3'
2: 5'-TCGGGGCATCGGAACCGCTCA-3'

每一逆转录混合物加水至 $100 \mu \mathrm{L}$, 然后从中各取 $3 \mu \mathrm{L}$ 用来扩增. 在每 $30 \mu \mathrm{L} \mathrm{PCR}$ 反应混合 物中含有 $50 \mathrm{mmol} \cdot \mathrm{L}^{-1} \mathrm{KCl}, 10 \mathrm{mmol} \cdot \mathrm{L}^{-1}$ Tris $-\mathrm{HCl}(\mathrm{pH} 9.0), 1.5 \mathrm{mmol} \cdot \mathrm{L}^{-1} \mathrm{MgCl}_{2}, 0.1 \%$ gelatin, $1 \%$ Triton $\mathrm{X}-100,100 \mu \mathrm{mol} \cdot \mathrm{L}^{-1} \mathrm{dNTP}, 20 \mathrm{pmol}$ 引物, $1 \mathrm{U}$ Taq DNA 聚合 酶, $3.7 \times 10^{10} \mathrm{~B} \alpha^{32} \mathrm{P}-\mathrm{dCTP}$, 扩增条件为 $94^{\circ} \mathrm{C} 1 \mathrm{~min}, 58^{\circ} \mathrm{C} 1 \mathrm{~min}, 72^{\circ} \mathrm{C} 1 \mathrm{~min} . \alpha_{1}-\mathrm{AR}$ 和 $\beta-$ $\mathrm{AR}$ 各亚型扩增循环数为 $29, \beta$-actin 扩增循环数为 20 . 阴性对照除了用逆转录阴性对照反 应混合物作模板外, 与上述反应完全一样. 扩增完毕取 $10 \mu \mathrm{L}$ PCR 混合液走 $8 \%$ 聚丙烯酰胺 电脉, 然后将胶做放射自显影. 其信号强度通过激光密度扫描来确定. 以 $\alpha_{1}-\mathrm{AR}$ 及 $\beta-\mathrm{AR}$ 各亚型扩增条带与 $\beta$-actin 扩增条带的信号强度之比来评定其 mRNA 的水平.

\section{2 结果}

\section{1 动物血浆 $\mathrm{T}_{3}, \mathrm{~T}_{4}$ 浓度}

对照大鼠 $(n=5)$ 血浆 $\mathrm{T}_{3}, \mathrm{~T}_{4}$ 浓度分别为 $0.59 \pm 0.16$ 与 $64 \pm 10 \mathrm{ng} / \mathrm{mL}$ 在腹腔注射 $\mathrm{L}-\mathrm{T}_{4}$ 大

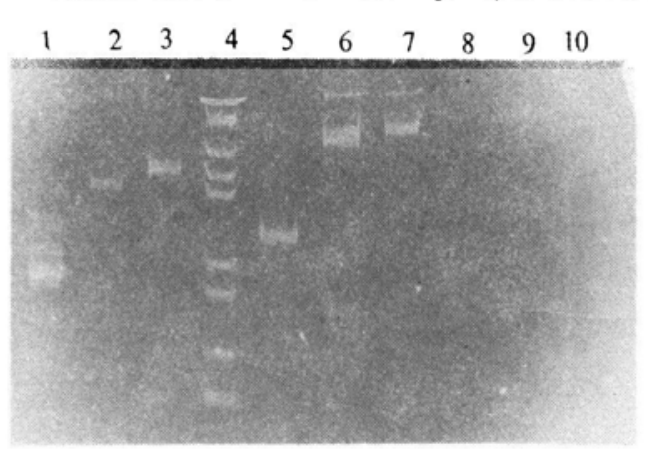

图 1 大鼠心脏 RNART-PCR 产物的聚丙烯 酰胺凝胶电泳

$1 \sim 3-\alpha_{1 \mathrm{~A}}, \alpha_{1 \mathrm{~B}}, \alpha_{\mathrm{ID}} \mathrm{mRNA}$ 扩增; $4-$ pGEM-Z-. Hae IIImarker; $5 \sim 7-\beta_{1}, \beta_{2}$-AR, $\beta$-actin mRNA 扩增; $8 \sim 10$ - 分别为对照, 甲状腺机能减低和元 进组 mRNA 在逆转录时省去 AMV 逆转录酶时的 扩增, 所用引物为 $\beta$-actin 引物 (阴性对照)
鼠 $(n=5)$ 血浆 $\mathrm{T}_{3}, \mathrm{~T}_{4}$ 浓度分别大于 9.1 与 $355 \mathrm{ng} / \mathrm{mL}$ 而在 $0.20 \% 2$-thiouracil 饮水大鼠 $(n=5)$ 血浆 $\mathrm{T}_{3} 、 \mathrm{~T}_{4}$ 浓度分别小于 0.5 与 $20 \mathrm{ng} / \mathrm{mL}$.

2.2 血浆甲状腺素浓度改变时大鼠心脏 $\alpha_{1}-\mathrm{AR}$ 和 $\beta-A R$ 亚型 mRNA 水平的变化

RT-PCR 扩增 $\alpha_{1 \mathrm{~A}}, \alpha_{\mathrm{IB}}, \alpha_{1 \mathrm{D}}, \beta_{1}, \beta_{2}-\mathrm{AR}$ 和 $\beta$-actin,. 其片段长度分别为 $156,287,304,213$, 388 和 $422 \mathrm{bp}$, 均与预期长度相符. 在逆转录阶 段省去逆转录酶时 PCR 扩增未见特异的扩增带 (图 1). 这表明特异性扩增带来自于 RNA, 而非 基因组 DNA. 在血浆甲状腺素浓度增高时大鼠 心脏 $\alpha_{1 \mathrm{~A}}, \alpha_{1 \mathrm{~B}}-\mathrm{AR}$ 的 mRNA 水平下降, 而 $\alpha_{1 \mathrm{D}}, \beta_{1}, \beta_{2}-$ ARmRNA 水平上升 (图 2(a)). 而在血浆甲状腺 
素降低时大鼠心脏 $\alpha_{1 \mathrm{~A}}, \alpha_{\mathrm{iB}}-\mathrm{ARmRNA}$ 水平上升, 而 $\alpha_{\mathrm{ID}}, \beta_{1}, \beta_{2}-\mathrm{AR}$ 的 mRNA 水平下降 (图 2(b)).
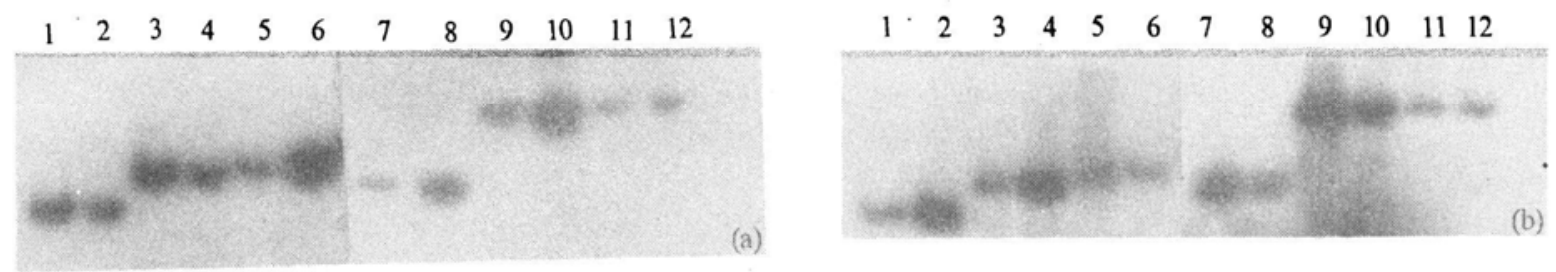

图 2 血浆甲状腺素浓度升高 $((a), n=5)$ 和降低 $((b), n=5)$ 大鼠心脏肾上腺素受体各亚型 $\mathrm{mRNA}$ 水平的改变

图示 RT--PCR 产物经聚丙烯酰胺凝胶电泳后的放射自显影结果; $1,3,5,7,9,11$ 分别代表对照大鼠心脏 $\alpha_{1 \mathrm{~A}}, \alpha_{1 \mathrm{~B}}, \alpha_{1 \mathrm{D}}$, $\beta_{1}, \beta_{2}-\mathrm{AR}$ 和 $\beta$-actin 的 mRNA 水平; 其余各例结果均与此相似

\section{3 讨论}

甲状腺机能立进时常伴有震颤, 心动过速, 焦虑等交感神经兴奋表现, 而甲状腺机能减退 时窦性心动过缓则提示交感张力下降, 然而血浆儿茶酚胺浓度在甲状腺机能六进患者正常或 反而下降,而在甲状腺机能减低患者反而上升, 因此上述交感神经张力的变化并不是由于血 浆儿茶酚胺浓度的改变所致,而可能与肾上腺素受体数目的改变密切相关.

关于甲状腺机能改变时大鼠心脏 $\beta-\mathrm{AR}$ 的改变已有很多报道, 发现在甲状腺机能立进与 减低时心脏 $\beta-\mathrm{AR}$ 密度分别增高与降低, 其介导的正性变力与变时效应也分别增强与减弱 ${ }^{[2]}$. 本文结果不仅在 mRNA 水平支持了以前的发现, 而且显示 $\beta_{1}, \beta_{2}$ 两种亚型都有显著变化.

近年来的研究证明 $\alpha_{1}-\mathrm{AR}$ 在交感 - 儿茶酚胺对心脏的调节中起重要作用 ${ }^{[]]}$, 因而甲状腺 机能改变时, 也可能有 $\alpha_{1}-\mathrm{AR}$ 的改变, 并因此影响心脏对交感 - 儿茶酚胺的反应性. 对甲状 腺机能立进时心脏 $\alpha_{1}-\mathrm{AR}$ 的改变目前报道比较一致, 即表现为数量明显减少 ${ }^{[3]}$; 但对甲状腺 机能减低时心脏 $\alpha_{1}-\mathrm{AR}$ 的改变则有较大分歧 ${ }^{[3]}$. 由于目前对 $\alpha_{1}-\mathrm{AR} 3$ 种亚型尚无理想的选择 性药物加以区分, 难以用放射配基结合和功能学的方法来分析心脏中 $\alpha_{1}-\mathrm{AR}$ 亚型的分布情 况. 因此, 对甲状腺机能改变时 $\alpha_{1}-\mathrm{AR}$ 亚型的研究很少. 本文首次报告在血浆甲状腺素浓度 改变时 $\alpha_{1}-\mathrm{AR} 3$ 种亚型在 mRNA 水平的改变, 即在甲状腺机能立进时心脏 $\alpha_{1 \mathrm{~A}}$ 及 $\alpha_{1 \mathrm{~B}}$ 的表达 降低而 $\alpha_{1 \mathrm{D}}$ 的表达增高, 在甲状腺机能减低时 3 种亚型的改变与甲状腺机能立进相反. 对于 这 3 种亚型特异性的改变在甲状腺机能立进与减低发病学中的意义有待明确 3 种亚型各自在 介导心脏活动中的作用有何不同后才有可能作进一步研究.

对于甲状腺素如何特异性地调节各种亚型的基因表达还不清楚. 已有资料表明 $\mathrm{T}_{3}$ 能与 核内受体结合, 这种受体复合物能与称为甲状腺反应元件 (TREs) 的特异 DNA 序列结合, 进 而调节 AR 基因的表达. 由于 TREs 的类型及位点不同, 以及周围 DNA 序列对它的影响可 能不同, 从而可能刺激或抑制肾上腺素受体各亚型的表达 ${ }^{[6}$. 确切的调节机理也有待于进一 步研究. 


\section{参考文献}

1 Ishac E J N, Pennefather J N, Handberg G M. Efect of changs in tyhroid state on atrial $\alpha$-and $\beta$-Adrenergic reœptors, adenylate cyclase activity, and catecholamine levels in the rat. J Cardiovas Phanmacol, 1983, 5: 396 405

2 Revell P, Pesclnl R, Muzzln $P$ et al. Changes in $\beta_{1}$ - and $\beta_{2}$-adrergicrecetor mRNA levels in brown lipose tissure and heart of hypothyroid rats. Biochem J, 1991, 277: 625 629

3 Hanft G, Gross G. The effect of reserpine, desipramine and thyroid hormone on $\alpha_{1 \mathrm{~A}}$ and $\alpha_{1 \mathrm{~B}}$-adrenoœptor binding sites: evidence for a subtype-specific regulation. Br J Clin Phamac, 1990, 30: 125s 127s

4 Chomczynski P, Sachi N. Singal-step method of RNA isolation by acid quanidinium thiocyanate-phenol-chloroform extraction. Anal Biochem; 1987, 162: 156 159

5 张幼怡, 禹更生, 陈明哲等. 大鼠左心房 $\alpha_{1}$ 受体及其亚型对 $\beta$ 受体正性变力效应的影响. 生理学报, 1994, 46: 473 479

6 Lazar-Wesley E, Hadoock H, Malbon C C et al. Tissue-specific regulationof $\alpha_{1 \mathrm{~B}}, \beta_{1}, \beta_{2}$-adrenergic recptor mRNAs by thyroid state in the rat. Endocrinology, 1991, 127: $1116 \sim 1118$ 